
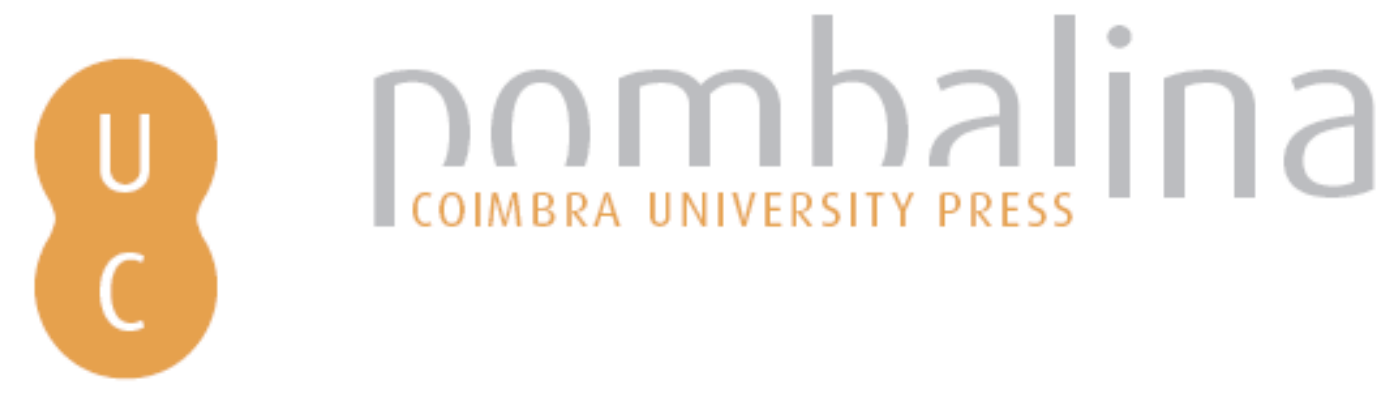

\title{
Sobre «As três culturas", de João Lobo Antunes
}
Autor(es):
Carvalho, Arsélio Pato de

Publicado por: Imprensa da Universidade de Coimbra; Gradiva

URL

persistente:

URI:http://hdl.handle.net/10316.2/32680

DOI:

DOI:http://dx.doi.org/10.14195/978-989-26-0389-6_11

Accessed : $\quad$ 26-Apr-2023 15:06:26

A navegação consulta e descarregamento dos títulos inseridos nas Bibliotecas Digitais UC Digitalis, UC Pombalina e UC Impactum, pressupõem a aceitação plena e sem reservas dos Termos e Condições de Uso destas Bibliotecas Digitais, disponíveis em https://digitalis.uc.pt/pt-pt/termos.

Conforme exposto nos referidos Termos e Condições de Uso, o descarregamento de títulos de acesso restrito requer uma licença válida de autorização devendo o utilizador aceder ao(s) documento(s) a partir de um endereço de IP da instituição detentora da supramencionada licença.

Ao utilizador é apenas permitido o descarregamento para uso pessoal, pelo que o emprego do(s) título(s) descarregado(s) para outro fim, designadamente comercial, carece de autorização do respetivo autor ou editor da obra.

Na medida em que todas as obras da UC Digitalis se encontram protegidas pelo Código do Direito de Autor e Direitos Conexos e demais legislação aplicável, toda a cópia, parcial ou total, deste documento, nos casos em que é legalmente admitida, deverá conter ou fazer-se acompanhar por este aviso.

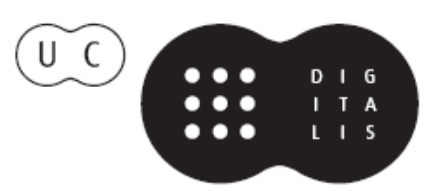


C I E N C I A I B E R T A

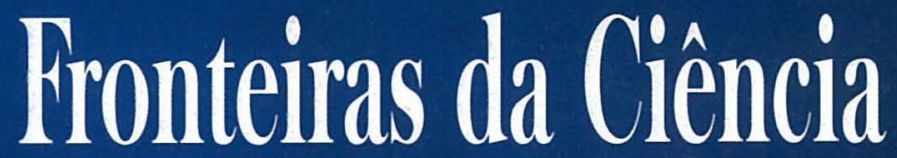

Desenvolvimentos Recentes - Desafios Futuros

RUI FAUSTO • CARLOS FIOLHAIS • JOÃO FILPE QUURRÓ

Coordenadores

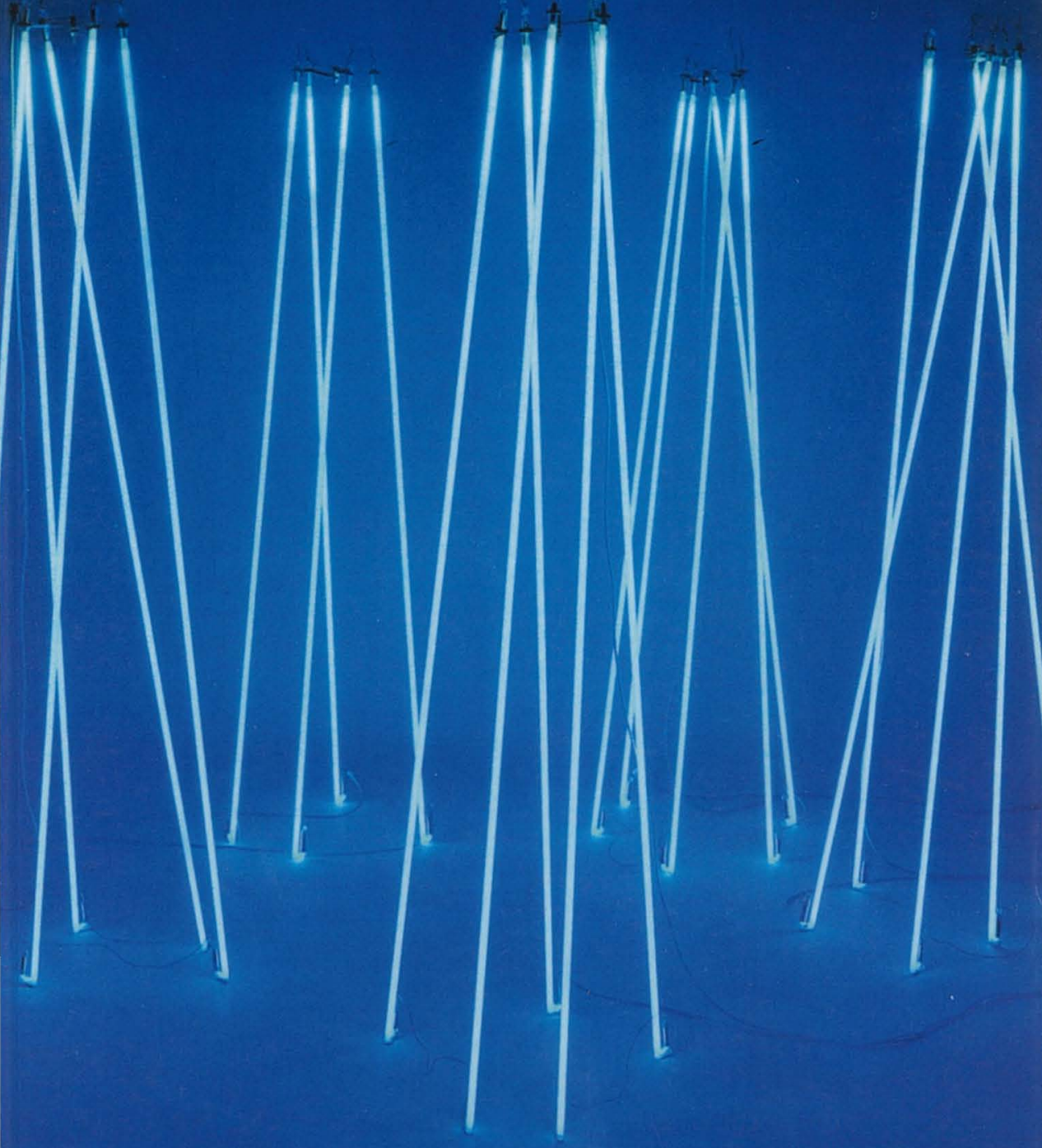

gradiva - Imprensa da Universidade de Coimbra 
(Página deixada propositadamente em branco) 


\section{RUI FAUSTO, CARLOS FIOLHAIS JOÃO FILIPE QUEIRÓ \\ Coordenadores}
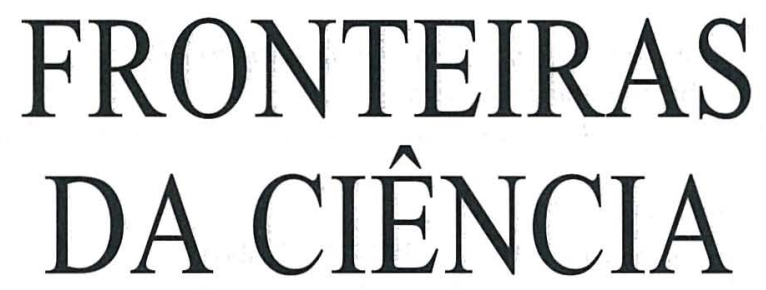

Desenvolvimentos Recentes Desafios Futuros 
(C) Gradiva - Publicações, L. da / Imprensa da Universidade de Coimbra, 2003 Coordenação editorial: Rui Fausto, Carlos Fiolhais e João Filipe Queiró Tradução: Jean Burrows, Vivien Burrows, Rui Fausto, Carlos Fiolhais e João Filipe Queiró

Revisão do texto: Isabel Pedrome

Capa: António Barros [Imprensa da Universidade. Coimbra], sobre imagem de «Águas Vivas», escultura de Silvestre Pestana, 2001

Foto: António Alves; Infografia: ESTÍMULUS [design]; Cortesia: Galeria Alvarez-Arte Contemporânea

Paginação: António Resende e Paula Isabel Jorge

Impressão e acabamento: G.C. - Gráfica de Coimbra, L. ${ }^{d a}$

Reservados os direitos para Portugal por:

Gradiva - Publicações, L. ${ }^{\text {da }}$ e Imprensa da Universidade de Coimbra

Gradiva - Publicações, L.da

Rua Almeida e Sousa, 21, r/c, esq.•1399-041 Lisboa

Telefs. $213974067 / 8 \cdot 213971357 \cdot 213953470$

Fax $213953471 \cdot$ Email: gradiva@ip.pt

URL: http://www.gradiva.pt

Imprensa da Universidade de Coimbra

Rua Antero de Quental, 195 • 3000-033 Coimbra

Telefs. 351239853110

Fax 3512398531 19・e-mail: fjrpress@ci.uc.pt

URL: http://www.imp.uc.pt

ISBN: 972-662-923-3

1." edição: Agosto de 2003

Depósito legal n. ${ }^{\circ} 199$ 463/2003 
Arsélio Pato de Carvalho

Departamento de Zoologia e

Centro de Neurociências

Universidade de Coimbra

\section{Sobre «As três culturas», de João Lobo Antunes}

A análise e a mensagem de João Lobo Antunes sobre as contradições e os paradoxos da profissão médica dão-nos a agradável sensação de que uma nova inteligência está a surgir dentro da profissão e de que um novo discurso emerge em prol dos seus valores tradicionais, não obstante a nova realidade duma cultura médico-industrial baseada no lucro. Esse discurso (e a acção correspondente) sensibilizará a classe médica para uma saída elegante e nobre da crise introduzida pela cultura empresarial, causada pelo progresso científico e pelo acesso universal aos cuidados médicos, que deslocaram o acto médico duma situação de grande autonomia pessoal, de grande altruísmo e solidariedade, para uma intervenção técnico-científica de grande exigência para o médico, como empregado do estado e de instituições privadas, ou como industrial por conta própria, que se rege pelas regras da economia do mercado livre.

Esta nova realidade, que tem criado uma imagem negativa da classe médica, que se funcionalizou, perdeu parte da sua independência e ficou sujeita às regras da cultura do capitalismo e da política, fomentará a modernização da medicina baseada em poderosas tecnologias, técnica e cientificamente exigentes, como a biologia molecular, a imunologia, a bioinformática, a terapia génica, a imagiologia e outras tecnologias emergentes, todas elas com custos que só o estado ou os complexos médico-industriais podem suportar. Em suma, a cultura da biotecnologia 
e da engenharia biológica-biomédica permeia profundamente o acto médico e constitui um desafio na formação dos novos médicos e na actualização dos que estão no activo.

A auto disciplina profissional e a reflexão da elite médica, a que pertence João Lobo Antunes, farão emergir uma nova cultura médica, que privilegie a formação de médicos técnica e cientificamente preparados para a prática da medicina moderna e preserve os seus valores éticos tradicionais. As faculdades de Medicina e os hospitais estão a ser confrontados com a necessidade de formar este novo médico. É necessário que este, perante os desafios da medicina moderna, possua uma grande auto-estima, que lhe advenha da sua competência científica e técnica, adquirida durante os primeiros anos da sua formação e nutrida com um constante aperfeiçoamento ao longo da sua carreira. Para isso, é necessário alterar profundamente a preparação do médico em Portugal. Li alguns dos escritos de João Lobo Antunes sobre esta matéria e notei com satisfação que o seu pensamento, assim como a sua experiência e prática, introduzem na cultura médica portuguesa os elementos necessários para a transformação essencial do ensino da Medicina à próxima geração de alunos.

Nas «Reflexões sobre a investigação médica em Portugal», do seu livro Um Modo de Ser, João Lobo Antunes contrasta a falta de experiência laboratorial típica do médico português, que ignora as técnicas de laboratório mais elementares, com a preparação dos colegas americanos, que adquirem uma formação científica antes de serem admitidos na faculdade. Cito: [...] o actual currículo médico, pela modéstia de visão de quem o gerou e pela rigidez intelectual de quem o mantém, não concede tempo ou espaço para que o estudante tenha um contacto, mesmo que reduzido, com um laboratório de investigação. A imobilidade curricular preservada pelos interesses particulares dos docentes tem contribuido de outras formas para o estado mais que mediocre da investigação médica. E mais adiante: Existe um fosso que se tem alargado entre clínicos e biólogos que está a afectar a nossa capacidade de aplicar o rápido progresso que vai ocorrendo. Portanto, é necessário assegurar que os médicos tenham formação científica para tirar vantagem dos avanços da biologia e das novas tecnologias médicas, cuja aplicação implica conhecimentos científicos e técnicos que não são normalmente transmitidos nos cursos de Medicina.

Apraz-me registar que João Lobo Antunes tem introduzido na Faculdade de Medicina de Lisboa alterações bastante profundas na formação dos alunos, promovendo o seu contacto com a investigação científica, e nas actividades de investigação científica de alguns 
departamentos, contratando biólogos nas áreas da biologia molecular, do desenvolvimento e das neurociências. Este padrão está agora também a ser seguido nas Faculdades de Medicina de Coimbra e do Porto. Tal tomada de consciência tem sido lenta, mas será irreversível, e o médico novo está aí a bater à porta! É minha opinião que a curto prazo deverá ocorrer uma revolução adicional que virá cimentar este processo de mudança na formação do novo médico e de outros profissionais da saúde. É oportuno alterar o esquema de admissões dos alunos nas faculdades de Medicina, criando uma quota de pelo menos $50 \%$ do numerus clausus para licenciados que tenham já feito uma formação científica. Deste modo, assegura-se que um número razoável de médicos tenha uma formação científica e encurta-se o período de formação destes alunos nas Faculdades de Medicina. É provável que por este método também se seleccione melhor um grupo de alunos com verdadeira vocação médica.

Voltando às três culturas de João Lobo Antunes, parece-me que elas têm pouco a ver com as duas culturas de C. P. Snow, que emergiram uma independentemente da outra. Por um lado, havia os literatos com a sua arrogância intelectual e ignorância do mundo científico que, no entretanto, tinha evoluído e estava a pulverizar as próprias premissas do seu pensamento literário e filosófico. Por outro, havia os cientistas que não souberam defender convenientemente, e popularizar, as implicações do seu trabalho. Não foi possível, salvo raras excepções, gerar intercomunicação entre estes dois grupos, e este aspecto é ainda patente no nosso ensino universitário. Muitos dos literatos ainda vivem à margem das principais ideias que permeiam a cultura científica, e os cientistas também não transgridem as suas fronteiras. A sua formação raramente inclui disciplinas de literatura, música, arte ou filosofia.

Uma terceira cultura, na sequência das duas culturas de C. P. Snow, surgiu nos últimos vinte anos quando cientistas e outros pensadores com formação científica começaram a ser bons divulgadores do pensamento científico em artigos e livros acessíveis ao grande público. John Brockman reuniu recentemente o pensamento de alguns destes divulgadores num livro intitulado precisamente $A$ Terceira Cultura. As ideias dos intelectuais da terceira cultura representam as fronteiras do conhecimento da biologia evolucionista, da genética, da física, da neurobiologia, da ciência dos computadores, etc. Os pensadores da terceira cultura são os novos intelectuais que fazem a ponte com o mundo moderno da ciência. É neste sentido que vejo João Lobo Antunes como um intelectual da nova medicina em Portugal, criador duma cultura nova, independente das três culturas que identifica no seu texto, que traçam o percurso da medicina em Portugal, e também em alguns outros países. O que emana do seu 
discurso é a visão de que as coisas não têm de ser como são e de que podemos preservar o que há de bom no acto médico tradicional, compatibilizando-o com as exigências modernas. João Lobo Antunes poderá ainda ter de fazer uma caminhada solitária, mas as ideias novas e os pensamentos profundos, capazes de modificar a maneira de pensar e de agir, surgem sempre duma minoria que faz sua a missão de transmitir um pensamento sério e de actuar em conformidade com esse pensamento.

Por coincidência, no próprio dia em que escrevi este comentário chegou-me às mãos o livro do Prof. Manuel J. Antunes (outro Antunes, este de Coimbra!) sobre $A$ Doença da Saúde. 
(Página deixada propositadamente em branco) 
 \\ A palavra "fronteiras" pode ser tomada em} diferentes sentidos. Pode referir-se aos limites, necessariamente provisórios, entre o conhecido e o desconhecido, ou aos limites entre o possivel e o impossivel, e, dentro do possivel, entre o desejável e 0 indesejável. Fronteiras podem também ser as delimitações, nem sempre nítidas, entre ciência e não-ciência, e dentro da ciência, entre as várias disciplinas. Quais são então as fronteiras da ciência?

Neste livro, a resposta a esta pergunta é dada, segundo as mais diferentes perspectivas, por um conjunto notável de personalidades, cientistas ou não, entre as quais se contam três Prémios Nobel.

Rui Fausto, Carlos fiolhais e JoÃo Fillipe Queiró são, respectivamente, professores de Química, Física e Matemática na Faculdade de Ciências e Tecnologia da Universidade de Coimbra. 